\title{
The importance of life and faith histories in the methodology of Practical Theology
}

\author{
Riet Bons-Storm (The Netherlands) ${ }^{1}$ \\ Research Associate: Department of Practical Theology \\ University of Pretoria
}

\begin{abstract}
The basic questions of Practical Theology concern the development of a community of faith built on, and building the faithful lives of its members in their particular contexts. This article is an exploration of the biographical method-as a means of qualitative empirical research - to obtain data concerning the possibilities of people in their everyday life of coming to an understanding of their particular situation in the light of their understanding of the Christian tradition. This understanding, individual faith develops in conjunction with the particular theological context in which a person lives her/his life. The author chooses to listen to the life and faith histories of people as a feminist. This means that the role gender plays in life and faith, is taken seriously.
\end{abstract}

\section{PRACTICAL THEOLOGY AND LIFE AND FAITH HISTO- RIES}

The basic questions of practical theology, guiding all its endeavours, concern the development of a community of faith built of, and building, the faithful and graceful lives of its members. As such, practical theology is concerned about "ordinary" people in everyday life. To become faithful and graceful, the members of the community of faith as embodied and, as such gendered, positioned actors - develop their own ideas about God and God's relation to them during their life and faith history. "Positioned" means: occupying a specific place in the network of socio-political relations in a society as it is

\footnotetext{
1 Prof Dr Riet Bons-Storm (emeritus professor at the University of Groningen, The Netherlands) is a member of the International Advisory Board of HTS, Teologiese Studies/Theological Studies. Prof Bons-Storm visited
} 
governed by ideologies. Ideologies order every culture, silently or sometimes explicitly, constituting hierarchies, giving power to some persons, marginalizing, silencing, ignoring or even oppressing others. "Power" can be understood as the extent of a person's ability - granted to her/him by a place in the hierarchy, justified by the reigning ideology - to influence the thoughts, emotions and actions of another person. Given this definition, $\mathrm{A}$ "position" also means the place a person has in the network of power relations - a place in the hierarchy determined in our society by the amount of authority a combination of factors provides: one's sex, the colour of one's skin, one's family name, one's age, whether one is able-bodied or not, the extent of one's formal education, one's wealth (for a more elaborate argument about power factors constituting a hierarchy in a society or group, see Bons-Storm 1992).

When a person is reared in the Christian tradition, her/his life and faith history, as told at a certain moment, is involved in a constant "conversation" - albeit not always explicitly - with the Christian tradition and the socio-political context s/he lives in. These conversations go on in the lives of people, trying to understand what the gospel as they heard and understood it - has to do with their everyday life in a certain sociopolitical context. Listening to a life and faith history, one hears not only the facts of a lifetime, but also the conversations related to these facts that go on in the mind of the telling person. These conversations reveal a certain hermeneutics: a manner of understanding the Christian tradition in the context of the life of a concrete person, relating to a community of Christian faith in one way or another, with a certain degree of commitment. This hermeneutics is very important for the practical theologian, whose discipline entails the generation of knowledge about the way people, in their various positions in a concrete society, can live their lives as faithful, graceful persons, building the community of faith in a particular place in the world. Life and faith histories show how, at a certain time and in a certain situation, a person tries to live a faithful and graceful life as a member of a community of faith.

So "life and faith history" refers to the narrative a person tells about her/his own life and the developments of what s/he experiences as "faith". It is an unwritten autobiography told, for instance, in a pastoral communication or to a researcher. The 
narrative is never a "true" report of what happened; it is not a documentary of a life, presenting the actual facts, but it is a painting, a work of art, giving meaning to "reality" from the narrator's point of view.

One can distinguish narratives from stories. There are a variety of opinions on this subject ( see Catherine Kohler Riessman 1993:18ff). A story can be understood as a unit in the whole of a narrative. "When we hear stories, for instance, we expect protagonists, inciting conditions, and culminating events" (Riessman 1993:18). A story has a plot. A narrative can be understood as a sequence of stories, looking for the plot of the whole lifetime. The listener tries to find out: why are these stories told as part of the life history as a whole? Undoubtedly there were other events in the life of the narrator which could also have been told. What is the relationship of one story to another in the narrative?

\section{TRYING TO UNDERSTAND EVERYDAY LIFE AND FAITH}

In practical theology it is still important to state the obvious: if we speak about "people", we have to take into account that it is not sufficient to speak about "people in general", "mankind", because different people experience life and faith quite differently in their everyday life, where practice and reflection go hand in hand. Everyday life stands for a mixture of various meanings. On the one hand it means the common, repetitive events concerning the most basic needs of human beings, body, mind and soul. It stands for the thousands of little and big things to be done to keep one's own life, a family, a workplace, a congregation going. On the other hand everyday life means the place for our "practices”. Rebecca Chopp states (1995:15-16): “...a practice is a pattern of meaning and action, that is both culturally constructed and individually activated... Practices involve full embodied actors." This means that everyday life contains an endless number of choices: what do we do with our time and why? Henning Luther understands everyday life as a flow of self-evidences that is broken repeatedly by contingencies and crises, when confusion and despair require the person to reorient her/himself. The crises are the loci of reflection on religion, on tradition and one's own faith (cf Henning Luther 1992:246). It is a matter of faith to assume that before one can express one's faith, one has to be touched by the Holy Spirit, God-in-action-and- 
communication, hearing the kerygma in one way or another, in one's own daily life. Not only the knowing about God is important for a faithful life, but also the experience - just fleetingly perhaps, just sometimes - that God really has something to do with and in one's everyday life (Stephanie Klein 1993:59).

Faith can be understood as the deepest convictions by which a person lives: it is trust in something or Somebody that one assumes to be truly reliable. Faith is a supporting hand under one's life, a bridge over troubled waters. Faith is a very complicated, multi-layered process, woven into the life history (Klein 1993:33). Faith or the absence of faith - is the outcome of one's hermeneutics as mentioned above: trying to understand the meaning of the Christian tradition in one's own life. This can be said of all faiths, but in this article I restrict myself to faith according to the Christian tradition. The Divine, according to this tradition and its canonized scriptures, is a liberating God, fierce and tender, transcending sex, skin colour, age as well as the physical or mental ability of people, taking them all up in Her/His passion for justice and grace, inspiring people to live faithful, graceful, liberated and liberating lives.

Because one may believe that this faithful and eternal God does not stop revealing Her/Himself to people, everybody can have the experience of revelation. Everybody can think about faith, built upon this experience of revelation, and try to find words that make this faith explicit in the particularity of one's unique human life. This does not mean that everybody's faith renders a graceful, liberating and liberated life. Neither a sophisticated university-educated theologian, nor a (so-called) "simple" layperson can guarantee that s/he interprets the touch of the Holy Spirit in the right way. Nevertheless, every person who articulates in her/his own words how s/he thinks God has worked in the world and in her/his own life, must be listened to as a possible theological agent. Nobody knows the truth in a perfect way. All theologies have to be contributed to the conversation about faith that constitutes a community of faith, from the sophisticated theologies of university-educated people to the theologies of laypersons who articulate their faith in their own words.

The faith of an individual shows the impact of theologies, as received in Christian education at home, in Sunday school, in sermons, etc. Sometimes people hear these theologies as if they are articulated in foreign languages, apart from their daily lives. This gives many of them a feeling of alienation and despair. Theologies shape our faith, 
but faith thought through shapes our theology. Theology is thinking about God and trying to articulate whom God may be and how God can be known, and it is always embedded in life. We do not - and even the most theoretical and detached theologian does not - think and articulate as a free-floating person. S/he is a positioned person with a certain life and faith history and a particular personality. Theology that is supposed to touch lives can only be developed if its thinking has come to a certain articulation that succeeds in bringing the kerygma home in the everyday lives of other people, all of them highly particular. Theology can be seen as the endeavour to try to find a language for the relationship between embodied, gendered, positioned persons and God. "The theologian must be engaged in 'a dialogue of life'”, writes Virginia Fabella (1989:115), a feminist theologian from the Philippines. The basis of every theology, practical theology included, is genuine interest in persons who live their daily lives in a particular context.

Faith is deeply influenced by experiences. Every position in society yields its specific experiences. Gender, race, and other qualities that give a person a particular place in the power-relations ideology prescribes, count. Trust, faith implies, can be shattered by specific events in one's life. Faith after a crisis will probably be different from faith before a crisis.

Knowing how individual people, in their relation to tradition and to their sociopolitical contexts, shape their own ideas and feelings about God and God's relation to them, may help to answer the basic questions of practical theology. We may be better equipped to discern and to organize practices in the faith community that help people to live their lives in a faithful, graceful way. We may be better equipped also to organize the dialogues of faith that build and sustain each community of faith. Life in the congregation means that we bring our life and its joys and sorrows into the community, in order to gain coherence in our life coram Deo. Telling and listening to life and faith stories - the autobiographical method - can therefore be useful in practical theology.

\section{ON CERTAIN CHARACTERISTICS OF THE LIFE AND FAITH HISTORY}

A life and faith history is often told at a certain point in a person's development, triggered by a certain event that disrupts the flow of everyday life and asks for a new orientation. Seeking order and meaning in one's life, one looks for an audience, a "neighbour", to 
help to find an answer to the question: who am I that I chose to do this or commit that particular act? Or: who am I that this or that came to pass in my life? Who am I, what is the thing to do now, the thing that fits me? I cannot believe anymore what I heard about God, about Jesus or the church when I was young. But if I admit that, to myself and to others, can I still be a member of the community of faith that is my spiritual home? If I admit that my faith has changed, do I still have anything that I can rely on? Have I up till now put my faith in what is not certain at all?

Listening to several faith histories, one may conclude that the ultimate question is: How can I be coherent and survive with dignity? Telling one's autobiography can be understood as a means to present, but also to look for an acceptable, coherent identity. "Acceptable" means: acceptable to oneself, in order to survive with a minimum of guilt and shame, acceptable also to one's important others, whoever they may be. "The autobiographer joins together facets of remembered experience - descriptive, impressionistic, dramatic, analytic - as she constructs a narrative that promises both to capture the specificities of personal experience and to cast her self-interpretation in a timeless, idealized mold for posterity", Sidonie Smith (1987:45) writes about the written autobiography. The same - although not as far as the "for posterity" bit is concerned can be said of the oral autobiography.

In an autobiography, the I tells the stories, constructing a coherent narrative, facing several questions: what shall I tell? What shall I not tell? How will the listener react if I tell this particular story? Shall I emphasize how I want to be or how I have to be? How can I make it acceptable that I did or did not behave in a certain way at a certain time? What does the listener want to hear? Does the listener have the power to punish me if I tell a story that can be considered as relating "improper" behaviour? Is my faith alright? Am I allowed by the powers-that-be in the church or society to express my faith in this manner? Do I have to defend my opinions? How can I do that? Will my particular faith, as it grew during my lifetime, be considered heretic, and will that endanger my place in the faith community? Do I want to lose that place? If not, should I invent a different story about my faith, more pleasing to the ears of the listener? How an autobiography takes shape depends on ideas the narrator has about the listener. As the life and faith history is told to somebody in particular, in a particular situation, it has the quality of an explanation, but also of a justification and even an apology of what one has 
done with one's life. The more the narrator sees her/himself as dependent on the listener, or as having lower status than the listener, the more the life and faith story becomes a justification or apology. However, even when narrator and listener share a common position and have the same social status, there is a certain quality of apology. Nearly everybody has doubts whether s/he has taken the right decisions at the important moments, the kairoi of one's life. Nearly everyone sees that the road that was not chosen was not altogether a bad one, nor was the chosen one in all aspects the right one. One feels that one has to justify and to defend one's choices also to oneself. The narrator usually interrupts the flow of the narrative - for instance at the end of a story - with: "Don't you think so?" or "Isn't it?". The listener has to resist the temptation to give an elaborate answer. Often such an answer is not really expected. The narrative will unfold itself further if a listener makes it clear in remarks and/or in attitude that s/he respects the choice of the narrator, whatever it was, without interrupting too much the flow of the narrative.

Joan Laird (1991) uses an interesting concept: the unstory. Some experiences stay "unstoried". They cannot be given a meaning that somehow fits into the fabric of a developing autobiography. This happens to experiences that are painful and shameful: they are put in a closet, the doors shut. To put those experienced events into words and to tell another person the story would mean not only letting the experiences, but also the pain and shame attached to them, out of the closet. One can only do this if one is absolutely certain that the listener will both understand and acknowledge the pain and shame and nevertheless accept the person who tells the story. An unstory usually contains an account of behaviour that clashes with the silent or explicit rules based on what the dominant ideology prescribes about specific roles, for instance gender roles. Gender is an important concept that orders a society and allots some roles to women, and other roles to men. The basis for this ordering, and for these roles, is sought in nature, biology, tradition, or God's will. "Race" is another important ordering concept, as are other features that determine one's place in the hierarchy in society and churches. Dominant ideology prescribes certain roles for women and for men, for Black persons and White persons, and so on, that are considered "proper", while other roles are “improper” (see Bons-Storm 1998:56). 
Groups of people that are marginal in the power-structures of a society are more dependent on the acceptance, the approval of listeners (pastors and researchers alike) than people who are considered members of the dominant group in our society: people who are male, White, not poor, able-bodied, heterosexual, with a lot of formal education. People who lack one or more of these features tend to feel insecure about themselves, their identity, the roles they have to or want to play. They have to live up to the standards of the dominant group. What Susan Layton says, in the novel The day of the scorpion by Paul Scott (1986:353), is a striking example of is:

I thought of it more as wanting a life for myself that would add up just like everybody else's life seemed to add up. I mean everyone seemed so sure, so awfully sure, and I wasn't. I was not sure at all. I thought, if only I could make a life for myself, a life like theirs, a life everyone would recognize as a life, then no one could come along and rob me out, no one would try.

I experienced another example during research on older women that resulted in my book: Kracht en kruis: Pastoraat met oudere vrouwen (Bons-Storm 2000:114). One of the 30 women whom I had asked for their life and faith history, 84 years old, reared in a rather strict Protestant tradition, asked me at the end of the interview, in which she had presented herself as a strong woman with a strong faith:

"You are a theologian, aren't you?"

"Yes, I am a theologian".

"But you are not a minister?"

"No, I am not a minister".

A short silence....: "Then I can ask you....", and she presented me with her serious doubts and confusion about the function of the Holy Spirit. I listened, my role of researcher changed into the role of pastor. I became concerned about her obvious distress, her attitude so different from the one she had presented during her narrative.

"Have you discussed this with your pastor?", I asked.

"No, what would he think of me!", was the answer. 
So, as a practical theologian, I have to start with listening, especially to people who have a position in society that silences their voices and mutilates their bodies. In our patriarchal culture many persons who feel subordinated live in a culture of being silenced. Amongst them are many women. Every practical theologian has to work, at least also, as a feminist. "A feminist is one who takes seriously the practical course of women's lives, the analysis and critique of these conditions of life, and the ways in which women's lives may become more fulfilling", writes Susan Parsons (1996:8). The same can be said about other groups of people, whose positions cause them to lack the authority and the power to speak that the dominant group in church and society possesses.

I argue that there is much wishful thinking about listening and empathy among practical theologians. The other will always be the other, even if we share a position in society, even if we like or love the other. Empathy across the gaps in position, caused by differences in skin colour, sex, amount of formal education, wealth, ableness of body, etc. is hard to obtain. Differences, also amongst women and amongst men, have to be acknowledged.

The good listener listens in two ways that can become one, without each way of listening losing its characteristics. One way of listening is fully to open to the narrator, taking in her/his embodied presence, attitude, non-verbal communication and narrative as a whole. If the narrative is used for scholarly purposes, the narrative has to be recorded and notes have to be made about the impression the embodied presence of the narrator makes on the listener.

Aside from this open listening, a critical way of listening stays important. Critical listening implies a certain distance to the narrator. Critical listening means hearing and discerning which powers distort the development of persons according to their God-given possibilities. An ideology-ridden society and the church judge them primarily as persons with a given sex, skin colour, etc. Careful listening to life and faith histories about people's everyday life, has to entail the notion of earned solidarity.

Keeping in mind that it can be assumed that the narrator looks for a certain coherence in the narrative, it is important to look for the formative force or event in her/his life, the starting point for her/his hermeneutics. To find this formative force one 
may pay attention to the way the narrator begins her/his narrative. Does s/he start at the beginning ("I was born in....My parents were....") or does s/he start with a particular subject, for example: "Now, I happened to be ill very often when I was little and that was very important in my life, for, you see,...", or "When I was fifteen I found out that I really was a lesbian and that...". Looking for coherence in the life and faith story implies that a narrator seeks integrity: an idea of who one is as a person whose thoughts, feelings, faith and acts are consistent.

Which kind of consistency? It may help to distinguish three ways of thinking about the self:

- how do I have to be?

- how do I aspire to be?

- how do I, deep down, think, hope, fear to be?

Some narratives make it quite clear that the narrator tries to find a coherence that will please a person of authority: the parents, a teacher, a minister, or God. The listener tries to understand why and when the narrator asks for the listener's approval, that is: why and when the narrative clearly has the quality of justification or apology. What is there to defend and why? Where and why can guilt feelings be heard? Who is really the protagonist of the narrative? Has the narrator found her/his own voice, does s/he trust her/his own counsel, also in matters of faith and theology? Does s/he speak with the voices of important others: a parent, a husband, a minister, a well-known theologian? Does s/he refer to proverbs or general sayings, for instance: "Well one must not complain. There is much to be grateful for"? Does the narrator present her/himself as an actor, an obedient follower of the powers-that-be in her/his life, a victim or a rebel - and how does s/he justify this presentation of self? Or is s/he not happy at all with the role s/he has played up till now because s/he has found out that she has lived by rules and roles, not chosen by her/himself but forced on her/him by ideologized convention?

Does the narrator stay near to what "actually" happened or does $\mathrm{s} / \mathrm{he}$ tend to draw an idealized picture? Every person is on the one hand "just like everybody else": daughter, son, young man, girl, wife, husband, mother, father, old woman, old man. 
Tradition shaped by ideology (Christian), custom and propriety supply the ideal behaviour for every situation and position. But everybody is also unique, relating one's acts in a certain manner to (Christian) tradition, custom and propriety. A listener has to be alert to hear "unexpected twists in the narrative that draw attention to differences from the conventional story", and "to locate the turning points that signal a break between ideal and real, the cultural script and the counter narrative" (Riessman 1993:30).

What are the points of reference of the narrator? What are her/his cultural resources? A political program, ideals about the quality of society, a certain ethics (based on what?), a Christian tradition, and if so: which and presented in what way? What is the role given to God, Jesus, the Spirit, the clergy, and the church in the narrative?

A very important point is to listen for what is omitted in the narrative. Which events or periods of time are unstoried? Sometimes events, unstoried in the beginning of the narration, become stories later on, if the listener shows in her attitude that s/he will not criticize the narrator.

A very important focus of critical listening is: what is the yearning that keeps this particular person going?

Critical listening to a life and faith history implies that one has to be aware of a complicated set of hermeneutics at work. The narrator gives meaning to her/his experiences, representing her/his life, faith and personality in a certain way, and the listener gives meaning to the narrative from her/his own perspective. The listener has to be conscious of her/his own embodied, positioned existence, always in a certain powerrelationship with the narrator. To detect the hermeneutics applied - mostly not fully consciously - by the narrator and by oneself as a listener, is one of the main features of the application of the biographical method in practical theology. Especially when listening to a faith history with many changes from belief to unbelief, a listener can become very insecure and even experience anxiety. When the narrator tells how s/he lost her/his faith in what was told her/him when s/he was young, the listener is confronted with alternatives of traditional belief. When a woman, for instance, tells how during her lifetime she lost her faith because she could not any longer accept that God was the almighty yet benevolent father, the listener has to reconsider how s/he her/himself thinks 
about the omnipotence of God and God's fatherhood. In cases like this critical listening can make open listening very difficult.

\section{THE ETHICS OF BIOGRAPHICAL RESEARCH}

The narrator needs to know how her/his narrative will be used. The researcher needs the narrator's consent to use the life and faith history. For that purpose the narrator must have the opportunity to read the transcript of the recorded narrative and affirm her/his consent to use the narrative - or parts of it - as recorded.

Using the narrative the researcher has to try and stay near to what is said by the narrator, avoiding a temptation to ignore individual particularities in order to arrive at general statements. The researcher, working on the transcripts of the narratives, has to be constantly aware of her/his own frame of reference, and of the viewpoint that is connected to her/his embodied, positioned existence. This awareness can help to avoid another temptation: to drown the meanings given by the narrator in the sea of the scholarly interpretation of the researcher.

If a psychological interpretation of the narrative/the narrator is attempted by the researcher - which is not always necessary, and should never be attempted by researchers not skilled in psychological analysis - the psychological school or method applied has to be clear. For instance: understood from a psychoanalytic standpoint, this or that meaning can be given to this or that story.

\section{THE PROBLEM OF GENERALIZATION}

Listening to life and faith histories - usually called "the biographical method", although it is actually autobiographies we listen to - can be qualified as a manner of qualitative empirical research. It is clear that elements of the life and faith histories of people, that are always different from one another, are entities that cannot simply be added up, because they are never of the same quality. If we would add up the experiences or opinions of different people, it would not make more sense than trying to add up apples and pears. One can say something about "fruit", but not about the specific qualities of an apple or a pear. The apple and the pear and their own specific qualities are lost in the addition. One cannot say anything about the necessary conditions of an apple that would make it a good part of a collection of "fruits". Everything that is said about "fruit" may not fit an apple, or a pear. People are far more unique than apples or pears. The same 
expressed opinion may have totally different meanings when coming from different persons. Qualitative research acknowledges the uniqueness and the 'otherness' of each and every person.

Another reason to opt for qualitative - and not quantitative - research is that people who are low on the hierarchical ladder of a society and, as such, do not easily trust their own counsel, are not trained to express their feelings and articulate their ideas. They are reluctant to fill in questionnaires that are to provide data for quantitative research, so their voice is often lost there. However, when they are listened to in an individual and open manner, they often are not only willing, but eager to tell their stories.

An autobiography is a narrative of an individual's life. Is there a way it can be understood as giving practical-theological knowledge about more than that individual's life?

The biographical method was developed predominantly by cultural anthropologists. In the first half of the $20^{\text {th }}$ century, in reaction to the growing use of - and faith in quantitative methods, they used the biographical method more and more often to obtain data, Paul Radin (1933:168, quoted by Aalten 1988:68), for instance, wrote that quantitative methods "rob cultural phenomena of their vitality, their humanity and of those special qualities that distinguish the cultural world of the biological or physical world." "In the eyes of Radin the wish to quantify reduced cultural data to unrelated data that could be used for intercultural comparisons" (Aalten, in Aaerts 1988:68). Radin, however, wanted to know what a particular culture meant to its different participants. An (auto)biography, according to Radin, can be used for scientific use if in one's general comments one stays close to what a narrator actually said and how it was said. Doing so, an image of the culture in which the individual lives can be obtained out of the individual life stories.

In pastoral work the individual's life and faith history tells us how to begin to understand this particular person. But that is not enough for practical theology as a whole. The pursuit of knowledge about a community of faith and factors that influence or determine it are always in the picture also.

Listening as a practical theologian to a life and faith history, one does not only want to know what happened in a life and what a person came to believe and put her/his faith in. The practical theologian wants to know how life and faith in a particular 
situation are intertwined, how this was experienced by a certain embodied person at a certain time in history, positioned in a certain society and culture, deeply influenced by ideologies. The unicity and totality of the embodied, positioned person has to be honoured. As such, every life and faith history can be understood as an example of the way a society and culture at a certain time influences - even constructs, to a certain extent - that specific individual, who is not just "a person", but always the gendered, positioned etc. person. A life and faith history tells us something important as a case-story. An individual does not live her/his life alone. She/he is embedded in a network of social relations, s/he is socialized in a specific culture. A person tells her/his story on the crossroads of:

- being a particular individual with physical, mental and emotional particularities and possibilities, experiencing particular events and happenings, making particular choices;

- being a member of a particular geographically based society and culture with its ideologies, being also a member of a specific sub-culture according to her/his qualities (being of a certain race, gender, class, religion, sexual orientation, age, etc);

- living at a particular time in history.

Listening to the life and faith histories of persons, who share a certain position in society and culture, one hears different stories, but the practical theologian can try to detect simlarities in their stories. For instance, I asked 30 older women in the Netherlands, all reared in Protestant homes, to tell me their life and faith history. Although they had many variables in common - gender, age, and what those two things imply in present Dutch culture, Christian denomination, having lived through the Second World War, having experienced economic hard times in the thirties and economic growth since the Second World War, having lived through a period of the growing emancipation of women and the ripples of the second feminist wave - their life and faith histories show a great variety. This is understandable, because there were also many variables they did not share: they varied in class, in the amount of formal education they had, in colour; they lived in big cities, small towns, small villages, some were lesbian, some heterosexual, 
some married, single, divorced or widowed; some lived in their own homes, others in homes for the elderly; some were still healthy and strong, some were ill or physically disabled (just in old age, or for a longer part of their life). Each had a particular set of parents, came from a particular family, had a particular personality/character. The ultimate goal of my research was to know more about good pastoral care, especially for women older than 60. Because I knew from personal experience and common sense how diverse older women were, taking into account also the fact that many older women in the Netherlands are rather shy to articulate their own ideas and feelings in public, I started my research by listening to what 30 women between the ages of 60 and 90 said about their faith, as it had grown or declined during their lifetimes. I heard all kinds of stories about that subject. Many of them said similar things. I did some comparing, but I tried to keep in mind that I did not look for "the same" thing, but for "some similarities" in their stories. Looking at all 30 stories and comparing them, I saw that women from a similar background, like a certain kind of Protestantism, and/or similar exposure to an emancipatory climate, or having lived through a divorce for instance, said similar things.

I detected some evidence in the research material of conditions that are crucial for certain specific developments in life and faith. I also found that certain specific events in the life-course and certain developments in faith influence each other in a particular way. Very carefully I tried to draw some more general conclusions about faith development in older women - in certain situations and positions - that may give directives to pastoral strategies in the faith community.

\section{HOW "UNIVERSAL" OR "GENERAL" DO OUR PRACTI- CAL-THEOLOGICAL CONCLUSIONS HAVE TO BE?}

As long as we work with embodied, gendered, positioned persons in practical theology, we have to resist the temptation of the epistemology of the natural sciences, promising "hard facts", or "the truth". As long as we grant that people have some possibility of choice, not understanding them as persons determined by their biology and environment, "natural science methods" can be escaped. By the way: some natural scientists themselves have much less faith in their methods than some practical theologians do. In nature there may be "facts"; in natural science - as in all scholarly efforts - their are only interpretations and opinions. Even full-scale quantitative research, sending out thousands 
of questionnaires, will render only a lopsided or much too "general" result. At the very least we have to ask: who filled in a questionnaire and who did not and, in both cases: why? Did a person feel s/he had to be honest, or did s/he give generally accepted answers? In both cases, we can never know why s/he did.

Practical-theological research needs to yield conclusions, however, that transcend the strictly individual. Practical theology tries to collect data in a scientific way. This means that research can be repeated, rendering the same conclusions that researchconclusions have to be falsifiable. Practical theology is concerned about the life and faith of living people. They can be understood, to a certain extent, as constructed by their socialization in a society, culture and point in history. They also are seen as subjects, making their own choices, determined by such a great amount of factors - many of them still unknown to science - that they are ultimately not predictable. It is impossible to make sweeping statements about people and their faith.

We can aim at a sufficient understanding of similarities to recommend a certain strategy-for-the-time-being in the community of faith, its teachings, its care, and its organization. As long as practical-theological research reaches this goal it contributes to the understanding of the faith-development or faith-decline of living persons in their various positions.

\section{Works consulted}

Aalten, A 1988. Naar het leven: Feminisme en biografisch onderzoek, edited by M Aerts et al. Amsterdam: Uitgeverij SUA.

Bons-Storm, R 1992. Pastoraat als Bondgenootschap: Aanzet tot vernieuwing van de kerkelijke praktijk vanuit het vrouwenpastoraat. Kampen: Kok.

Bons-Storm, R 1998. The incredible woman: Listening to women's silences in pastoral care and counseling. Nashville Tn: Abingdon Press.

Bons-Storm, R 2000. Kracht en kruis: Pastoraat met oudere vrouwen. Kampen: Kok.

Chopp, R S 1995. Saving work, in Feminist practices of theological education. Louisville, Ky: Westminster John Knox.

Fabella, V 1989. A common methodology for diverse Christologies?, in Fabella, V \& Oduyoye, M A (eds), With passion and compassion: Third World women doing 
theology. Maryknoll, N Y: Orbis Books.

Klein, S 1993. Theologie und empirische Biographie-forschung. Stuttgart: Verlag W Kohlhammer.

Laird, J 1991. Women and stories: Restorying women's self-constructions, in McGoldrick, $\mathrm{M}$ et al (eds), Women and families: A framework for family therapy. New York: Norton, 1991

Luther, H 1992. Religion und Alltag, in Bausteine zu einer praktischen Theologie des Subjekts. Stuttgart: Radius Verlag.

Parsons, S F 1996. Feminism and Christian ethics. Cambridge: Cambridge University Press.

Radin. P 1933. The reaction against the quantitative method, in The method and theory of ethnology: An essay in criticism. New York: Basic Books.

Riessman, C K 1993. Narrative Analysis. Newbury, London, New Delhi: SAGE Publications.

Smith, S 1987. A poetics of women's autobiography: Marginality and the fictions of selfrepresentation. Bloomington: Indiana University Press.

Scott, P 1986. The day of the scorpion. London: Panther Books, Granada Publishing. 